International Journal of Engineering \& Technology, $7(2.15)(2018) 150-153$
International Journal of Engineering \& Technology
SPC
Website: www.sciencepubco.com/index.php/IJET
Research Paper

\title{
A conceptual framework on constructing effective learning content for programming novices
}

\author{
Swee Ling Chean ${ }^{1,2 *}$, Sin Ban $\mathrm{Ho}^{2}$, Ian Chai ${ }^{2}$ \\ ${ }^{1}$ Lee Kong Chian Faculty of Engineering and Science, Universiti Tunku Abdul Rahman, 43000 Kajang, Selangor, Malaysia \\ ${ }^{2}$ Faculty of Computing and Informatics, Multimedia University, 63100 Cyberjaya, Selangor, Malaysia \\ *Corresponding author E-mail: karenchean@gmail.com
}

\begin{abstract}
An e-learning system provides a platform for communication between the educators and the students. It facilitates the sharing of information and learning content in a form, which can be easily accessed by the users. In e-learning educational systems, a learning content management system (LCMS) is commonly used for developing and managing learning content. An overly comprehensive LCMS might not suit the needs for all domains such as learning programming for novice learners. Teaching novice programming learners is not an easy task as mentioned in many studies. Complicated explanations and boring teaching methods cause loss of interest in learning programming. Many educational studies have been carried out with different aspects and approaches to improve teaching and learning programming in school and tertiary levels of study. This paper proposes a conceptual framework for constructing effective learning content. It is challenging for Malaysian educators to design and prepare learning content that allows programming novices to learn at their own pace and skill levels. It is believed that an effective learning content framework would benefit educators who intend to start teaching programming to novices.
\end{abstract}

Keywords: E-learning content; Learning content management system (LCMS); Multimedia; Programming; Virtual learning environment (VLE).

\section{Introduction}

Rapid development of information and communication technologies (ICT) has impacted on every aspect in human society. One of the aspects is in education. Many institutions and educators have moved towards a new study form - e-learning. In e-learning educational systems, a learning content management system (LCMS) is commonly used for developing and managing learning content. An LCMS is a computer application that provides a platform for creation, development and management of learning content. This is achieved by using a central object repository, usually a database which stores learning materials that are searchable and adaptable to any on-line course $[3,6]$ (see Figure 1 for the LCMS architecture). The platform manages the experience of learners as they interact with e-learning content [6]. In addition, the platform is usually a multi-user environment that allows sharing of materials and interaction among users $[3,6]$.

The introduction of e-learning has enhanced traditional classroombased teaching practices with new techniques that provide revolutionary learning experiences for learners. Educators can create learning content and share it through a virtual learning environment (VLE) containing teaching tools. Learners can learn no matter where they are without the restriction of time and space.

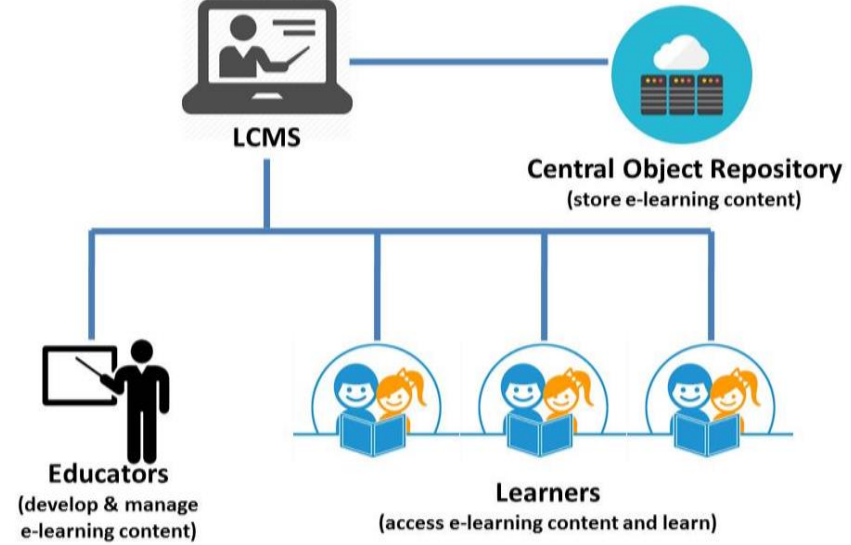

Fig. 1: The LCMS architecture

This paper is organized as follows. Section 2 discusses the problem in teaching and learning programming using VLE. Section 3 presents the background, motivation and objectives. Section 4 introduces related works. Finally, this paper proposes research approach and data needs in the last section.

\section{Problem in teaching and learning pro- gramming using virtual learning environ- ment}

To learn programming, one must study programming syntax, various control structures, programming paradigms and most im- 
portantly, apply them in designing a solution to the problem. Programming tools that provide comprehensive facilities for program development and implementation are also needed.

Teaching novice programming learners is not an easy task, as shown in many studies, because it involves the understanding of abstract concepts, logical thinking and problem-solving skills [2, 7, 9-10]. The common approach of designing e-learning content is just replicating teaching content from traditional methods to forms that can be uploaded to a VLE. The arrangement of the content usually starts with a list of topics such as data types, program input and output, selection and making decisions, loops and so on In each topic, the introduction starts with its background or motivation followed by terminologies, rules of application and control flow. Lastly, sample code and case studies with solutions are presented. With this arrangement of learning content, learners canno relate the terminologies and rules to the code implementation. Complicated explanations and boring teaching methods cause them to lose interest in learning programming. Many educational studies have been carried out with different aspects and approaches to improve teaching and learning programming in school and tertiary levels of study such as learning programming languages in their own mother tongue [10], the use of video learning objects [1, $10]$, the use of program visualization tools [7, 9], etc.

According to an online survey done on computer science educators by a working group convened at ITiCSE, general-purpose LCMSs are short on features that meet certain needs specific for learning computing and programming such as lack of support for integration of program visualization tools. They also limit the user to a certain way of course design, topic coverage and course management [9].

\section{Background, motivation and objectives}

Science, Technology and Society (STS or Science and Technology Studies) is the study of the relationship between scientific research and technological innovation and society, politics and culture. According to Sheila Jasanoff, Pforzheimer Professor of Science and Technology Studies at the Harvard Kennedy School, technological innovation always follows the ideas of goodness for social outcomes [4]. Programming is believed to be an important driver towards higher thinking skills. It can enhance cognition in individuals in knowledge, attention, analysis, evaluation, creation, decision-making, logical reasoning, etc. It also becomes a sort of literacy that children cannot live without in the 21 st century.

Programming courses are usually conducted at the tertiary level of study in Malaysia. In 2016, a competition called the National Code Challenge started with project submission by the participants of a government funded programme, Coding@Schools. In the Coding@Schools 2016 programme, approximately 1,500 students from 50 participating schools nationwide were trained and challenged to form a team to create websites or apps. Selected works were chosen to be submitted to the National Code Challenge. The competition received a good response and the judges were impressed by the overall quality of the submissions.

Many IT specialists were inspired and developed a keen interest in computer science and technology when they were in school. However, they did not know where to start. Teaching programming to school students is not new. Code.org, launched in 2013, provides online self-guided tutorials and activities for women and students of all background to have the opportunity to learn computing and programming wherever they are. Based on the educators and students' level, they provide creative and fun tutorials called The Hour of Code in hour-long segments for all ages in over 45 languages. The team at Code.org includes expert facilitators and professional learning partners. Malaysia is a new player in teaching programming using VLE. Many institutions and schools in Malaysia are conducting programming courses using classroom-based teaching practices. The use of VLE is mainly for disseminating information and learning content to students. The learning content is also designed to facilitate conducting lectures rather than for self-learning. Face to face contact between novice programming learners and teachers is always required to achieve effective learning. It is therefore challenging for Malaysian educators to design and prepare learning content that allows students to learn at their own pace and skill levels. It is believed that the study of necessary factors for the successful adoption of LCMS in programming will benefit those educators who intend to start teaching programming in Malaysia.

For the problem mentioned in section 2, we attempt to achieve three research objectives as follows:

- To propose a framework for constructing effective learning content to improve programming novices' achievement.

- To empirically investigate the effects of different learning content approaches on novices of a programming language.

- To investigate how well the particular learning content framework performs with different learning styles of programming novices.

\section{Related works}

Many theorists have tried to formulate theories about how elearning takes place, in attempts to provide better support for programming education. Some of these works have brought different approaches explaining how e-learning takes place. This section highlights four studies of the relevant approaches.

In 2008, L. A. Bexheti had done a research on comparison and evaluation of different LCMSs and developed an LCMS using a modular approach, architecture and conceptual design in South East European University, Macedonia [3]. The developed system contains the following modules:

- User Management module for enrolment of students and assigning user roles for participants.

- $\quad$ Course Management module for managing course activities.

- Resource Module for uploading and maintaining files in the server.

- Lesson Module for organizing lessons in a hierarchy.

- Assignment Module for managing submission of assignment.

- Quiz Module for setting and marking quiz questions.

- News Module for news announcements.

- Messaging Module for sending messages to a group or a single user.

- Calendar Module for adding or sharing events.

- $\quad B L O G$ Module for blogs and comments.

The developed system by L. A. Bexheti reduced the time to disseminate information to students through content management, provided a qualitative learning content in a form which can be easily accessed by users, increased communication between users through messaging and calendar modules, saved printing cost through the quiz module, and increased reusability of the content. Figure 2 presents the overview of the system modules and the strengths of the system. In addition, L. A. Bexheti highlighted the possibility of upgrading the system with new features by using a modular approach. 


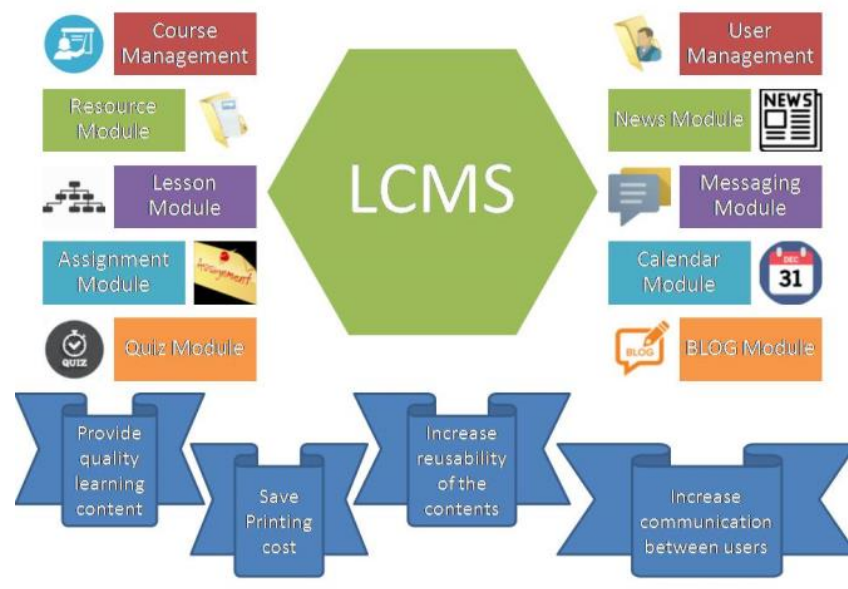

Fig. 2: An overview of the system modules and the strengths of the system

There are many factors contributing to the success of the adoption and implementation of e-learning. In [5] studied the possible factors and proposed a conceptual framework for e-learning in secondary schools. The framework consists of six dimensions: student, teacher, course, design, technology and support (see Figure 3 for the dimensions of the e-learning framework). Students who possess positive attitude and good learning culture will be motivated to learn. A creative and lively teaching style can motivate the students towards e-learning. Teachers need enthusiasm to improve their teaching materials and practice. A well designed elearning system should be easy to use and the content should be useful and of good quality. In addition, management and government support with a good and pleasing environment and sophisticated information technology is important.

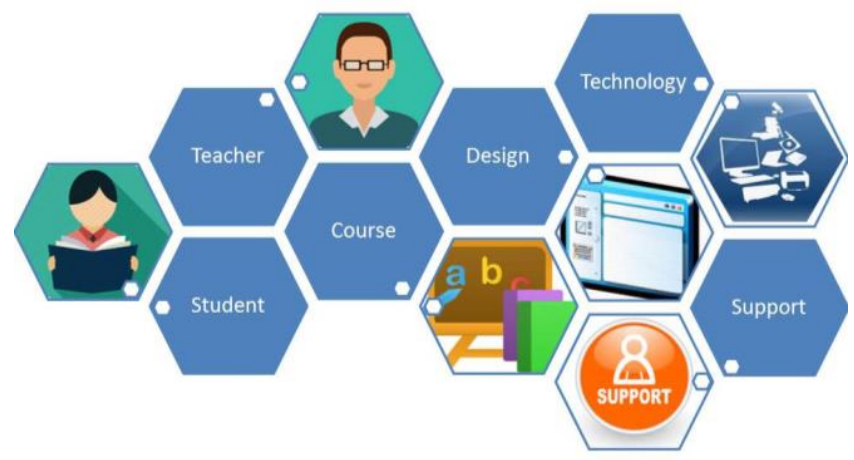

Fig. 3: The dimensions of the e-learning framework

To attract students and help them to maintain positive attitude to learn programming, the following two related works attempted to improve teaching methods and course design with different approaches.

In 2015, ontology-based learning approach proposed by [6] emphasized creating personal collections of learning resources for managing the experience of learners. Software architecture for learning resource retrieval and integration into personal collections was designed. The architecture includes interface, logical and data levels. It was implemented by using the reasoning engine Racer Pro. In the study, a software tool was developed to create personal collections for the course "Programming Languages, $\mathrm{C}++$ " in Volgograd State Technical University. Testing was done to collect the average time of collection creation and the average value of collection recall. The test also compared the autogenerated collection with the collection created by tutors. The result had shown that the models, method and software tool developed are effective and efficient for creation of new personal learning content.

Another study was done by [7]. In their study, learner control and motivation are the two main issues in an e-learning environment.
The paper suggested the learner's control and understanding could be improved through visualization and motivating the learners through gamification. In the study, animations were used to present executing programs and algorithms to an experimented group of university. There were two types of prototypes: iterative visualization for imperative for-loop and object visualization for objectoriented [8] code. This was compared with the other group of students which was given an ordinary lecture, that is explaining program code on a whiteboard without the visual display of the dynamic parts of program execution. The data collection was mainly from course evaluation questionnaires. Overall, the result showed that the lecture with visualization software was clearer and a more effective way of transferring knowledge. The gamebased learning used the progress bar and digital badges as part of the course component. It aimed to create a game feel to stimulate the students to learn. However, the game feel environment was not significant in motivating the students. In addition, there were courses on e-learning conducted for university teachers by [7]. The content was about the development of digital learning material. From the discussions and comments at course seminars, the feedback was generally positive. The university teachers commented that the e-learning with visualization software and other digital learning resources was useful for them but the workload was too heavy for the number of credit hours.

\section{Research approach and data needs}

A good product does not necessary have the most features, but should have the right features that people need and certainly not lack of a necessary feature. An overly comprehensive LCMS might not suit the needs for all domains, in particular programming for novice learners.

Programming is a problem-solving activity. To solve a problem, the problem needs to be stated clearly to make sure the requirement is clearly understood. And, the data to work with (input) and the results to produce (output) need to be identified. This is followed by the design of an algorithm and implementation of the algorithm by writing a program in a programming language to match the steps of the algorithm (see Figure 4 for the steps to solve a programming problem). Novice student learners solely relying on learning content faced a number of difficulties in learning a programming language for problem solving. One of the difficulties that often arises for them is that the problems and their solutions are complex. No single chapter in the learning content is sufficient to explain everything needed for complex solutions as students work through the process of developing solutions. The research will investigate these reasons to find ways of improving an LCMS for programming-related courses.

\section{Problem Solving}

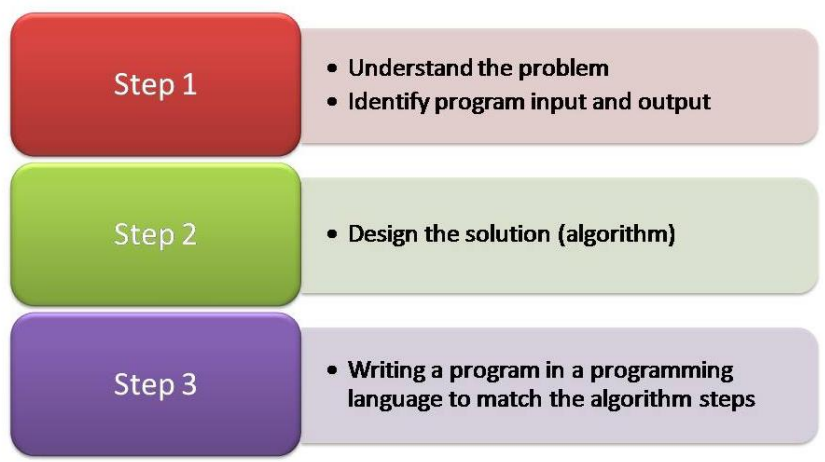

Fig. 4: Steps to solve a programming problem

The scope of the research revolves around the idea that an LCMS should be proficient enough to help programming novices learn how to program in a self-guided way. It studies the effects on the 
students at a tertiary level of study. This study focuses in analyzing the effectiveness of approaches on novice student learners of a programming language.

Research will be carried out in the form of an empirical study. In order to test the hypothesis of our experiment, learning content will be redesigned and an improved LCMS using the proposed approach will be developed. The different approaches of the improved and existing LCMSs will be tested on a programming language course. This will examine how well each approach performs in guiding students as they learn to solve programming problems on their own.

For the experiment, selecting suitable subjects is important. The experimental subjects will be selected from the students at a tertiary level of study who enroll for a programming course for their first time. They would be suitable for the experiment because in general, they have some knowledge about computers but most of them would be first time learners for the particular programming language.

Collected data will be analyzed using tools such as AMOS (Analysis of Moment Structures). Suitable methods for analyzing the data will depend on the type of data collected and shall be decided upon later. For consistency, the data will be tested for any difference of mean (on selected dependent variables) between the groups using different approaches.

\section{Conclusion}

There is a growing trend towards e-learning in today's educational system. Malaysia news on July 2016 reported that the Malaysian Digital Economy Corporation (MDEC) CEO Datuk Yasmin Mahmood has announced that coding will be officially added to the syllabus of national schools starting 2017. According to her, the program was in line with the Malaysia Education Blueprint 2013-2025 for encouraging cognitive and higher order thinking as well as embedding IT as a teaching and learning tool. Many have developed and continue to develop computer-based software and tools that aid in management, teaching and learning in computer science courses ${ }^{9}$. The need for LCMS is more crucial than ever. There is still room to improve in LCMS as the existing systems do not cater for all types of learning. The research would investigate how to enhance the systems to better support programming education.

\section{References}

[1] Ali SI (2013), Media content analysis for creation and annotation of video learning objects. $\mathrm{PhD}$ thesis, University of Oslo.

[2] Suliman A, Hawari R \& Othman M (2011), Preliminary study of teaching programming at a Malaysian school. Proceedings of the 3rd International Conference on Computing and Informatics, pp. 127-132.

[3] Bexheti LA (2008), Development of a learning content management system. WSEAS Transactions on Information Science and Applications 5, 1001-1010.

[4] Hassler S (2016), STEM crisis? What about the STS crisis? IEEE Spectrum. https://spectrum.ieee.org/at-work/education/stem-crisiswhat-about-the-sts-crisis.

[5] Haw SK, Haw SC, Wong CO \& Lim YP (2015), LearnCube: A conceptual framework for e-learning implementation in secondary school. Indian Journal of Science and Technology 8, 1-7.

[6] Kultsova M, Anikin A, Zhukova I \& Dvoryankin A (2015), Ontology-based learning content management system in programming languages domain. In A. Kravets et al. (Eds.) Creativity in Intelligent, Technologies and Data Science Volume 535 of the series Communications in Computer and Information Science. Cham: Springer International Publishing, pp. 767-777.

[7] Olsson M, Mozelius P \& Collin J (2015), Visualisation and gamification of e-learning and programming education. Electronic Journal of E-Learning 13, 441-454.

[8] Raghuveer VR \& Tripathy BK (2012), An object oriented approach to improve the precision of learning object retrieval in a self learning environment. Interdisciplinary Journal of E-Learning and Learning Objects 8, 193-214.
[9] Rößling G, Joy M, Moreno A, Radenski A, Malmi L, Kerren A, Naps T, Ross RJ, Clancy M, Korhonen A \& Oechsle R (2008), Enhancing learning management systems to better support computer science education. ACM SIGCSE Bulletin 40, 142-166.

[10] SivaKumar R, Jayachandran G \& Marx MA (2014), A study of flaws in transporting programming languages and emerging a platform to impart programming in a reasonable approach. Asia Pacific Journal of Research 1, 121-125. 